
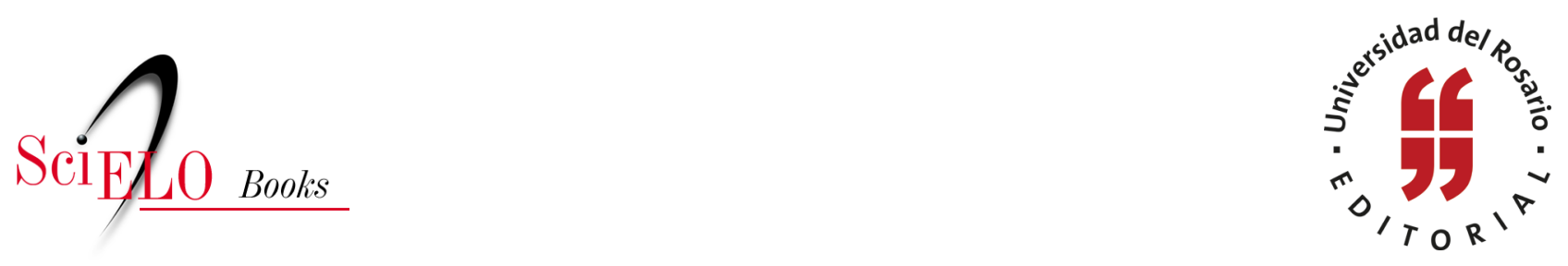

\title{
6. El seguro ecológico y la responsabilidad ambiental en Colombia
}

\author{
José López Oliva
}

\section{SciELO Books / SciELO Livros / SciELO Libros}

LÓPEZ OLIVA, J. El seguro ecológico y la responsabilidad ambiental en Colombia. In: AMPARO RODRÍGUEZ, G., and VARGAS CHAVES, I., ed. Perspectivas de responsabilidad por daños ambientales en Colombia [online]. Bogotá: Editorial Universidad del Rosario, 2015, pp. 163-193. Textos de Jurisprudencia collection. ISBN: 978-958-738-644-8. https://doi.org/10.7476/9789587386448.0007.

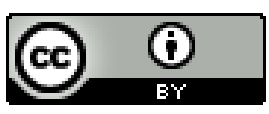

All the contents of this work, except where otherwise noted, is licensed under a Creative Commons Attribution 4.0 International license.

Todo o conteúdo deste trabalho, exceto quando houver ressalva, é publicado sob a licença Creative Commons Atribição 4.0.

Todo el contenido de esta obra, excepto donde se indique lo contrario, está bajo licencia de la licencia $\underline{\text { Creative }}$ Commons Reconocimento 4.0 . 


\section{El seguro ecológico y la responsabilidad ambiental en Colombia}

José López Oliva*

\section{Introducción}

El Estado colombiano expide algunas normas con el propósito de prevenir, controlar y sancionar las conductas que comporten la contaminación del ambiente y, a su vez, indemnizar a las víctimas de la responsabilidad ambiental civil o estatal, a través del seguro ecológico; acto jurídico que busca, adicionalmente, la protección del patrimonio de las empresas o personas naturales, potenciales generadores de daños al medio ambiente. El objetivo del seguro ecológico, obligatorio o voluntario, no es el de mejorar y conservar los recursos naturales, así como tampoco priorizar el desarrollo sostenible o la biodiversidad del país, considerada como patrimonio nacional. La finalidad del citado seguro es salvaguardar los derechos de quien en el ejercicio de exploración y explotación de los recursos naturales pueda generar un daño ambiental; actividades catalogadas como peligrosas, donde se aplica el régimen objetivo de responsabilidad sin culpa, con una dimensión social.

La minería legal e ilegal y el transporte en todas sus modalidades son ejemplos de actividades donde se aplica la denominada 'teoría del riesgo' con

* Abogado; magíster en Derecho de la Universidad de los Andes; magíster de la Universidad Carlos III de Madrid (España); especialista en Derecho Comercial de la Universidad Pontificia Bolivariana de Medellín y en Derecho Penal y Probatorio de la Universidad del Rosario; candidato a doctor en Bioética en la Universidad Militar Nueva Granada, con pasantía de investigación doctoral en la Facultad de Derecho de la unam (México). Docente certificado a nivel internacional por la Life Office Management Asociation, Inc. - Loma, con sede en Atlanta, Georgia (EE. UU.); tratadista y ensayista de textos de contenido socio-jurídico; profesor e investigador de la Universidad Militar Nueva Granada; director de la Línea de Investigación de Derecho de la Responsabilidad y de Seguros; conferencista nacional e internacional en Argentina, Perú, Paraguay, Bolivia, Ecuador, Panamá, Costa Rica y México. Correo electrónico: jose. lopez@unimilitar.edu.co 
presunción de responsabilidad ambiental. El propósito del presente texto es resaltar la importancia que constituye la protección constitucional y legal de los recursos naturales, y la defensa de la vida en todos sus contextos, que debe desarrollarse en un medio ambiente sano, instituido este como un derecho humano que demanda protección. Así las cosas, la protección del medio ambiente debe hacerse con el establecimiento de políticas públicas adecuadas y pertinentes. El seguro ecológico, como acto jurídico bilateral, aleatorio, oneroso y de ejecución sucesiva, tiene diversos objetivos, en los que no se incluye la protección del medio ambiente.

El presente texto es resultado de una investigación de naturaleza exploratoria de reflexión, analítica e interpretativa de tipo bibliográfico, en la que se agruparon y sistematizaron los documentos relacionados con el tema objeto de la investigación. Él revela una investigación exploratoria de revisión bibliográfica con análisis de contenido, que se desarrolla de la siguiente manera: en principio, (1) se hace alusión a las disposiciones constitucionales relacionadas con el medio ambiente y, enseguida, (2) se identifican las tensiones existentes entre la protección del medio ambiente y la explotación de los recursos naturales con un propósito económico. A su vez, se estudia (3) el régimen de responsabilidad ambiental aplicado en Colombia y se continúa con el (4) estudio y análisis del seguro ecológico dispuesto por el legislador, (5) se relacionan los intervinientes en el nombrado contrato y se realiza un breve análisis del (5.5) sistema claims made, en el seguro de responsabilidad civil por daño ambiental. Al final, se exponen las conclusiones de la investigación.

\subsection{Disposiciones constitucionales relacionadas con el medio ambiente}

En la Constitución Política de Colombia, se indica que el saneamiento ambiental es el conjunto de acciones de carácter técnico, social y económico, encaminadas a la protección de la salud, y tiene el propósito de alcanzar niveles considerables de salubridad ambiental. Dicho saneamiento comprende los procedimientos de manejo sanitario del agua potable, residual y excreta, así como también el manejo adecuado de los residuos sólidos, con el objetivo de prevenir la contaminación del ambiente y, por consiguiente, proteger la salud de las personas que cohabitan en una zona rural o urbana determinada (Constitución Política, 2013, art. 49). 
Así mismo, se instituye que el Estado debe procurar el bienestar general y la calidad de vida de las personas, y satisfacer sus necesidades de saneamiento ambiental, salud y agua potable; por lo tanto, la asignación de recursos debe ser prioritaria para la satisfacción de las citadas necesidades (Constitución Política, 2013, art. 366). A su vez, se impone al Estado y a las personas que lo integran la obligación de proteger las riquezas tanto culturales como naturales de la nación, y evitar la generación de daños derivados de responsabilidad ambiental que lesionen los intereses de las comunidades (Constitución Política, 2013, art. $\left.8^{\circ}\right) .{ }^{1}$ En suma, todas las personas que habitan el territorio nacional tienen derecho a gozar de un ambiente sano, y, por esta razón, es relevante involucrar a la población potencialmente afectada en las decisiones que puedan alterar su entorno ambiental diverso.

La diversidad de la flora y fauna existente en el país debe ser conservada; máxime cuando se trate de áreas de preservación ecológica protegidas por el Estado, y que los particulares deben preservar, razón por la cual se requiere establecer un programa de fomento y educación destinado a la población (Constitución Política, 2013, art. 79). Ciertamente, para la salvaguarda de los recursos naturales y para evitar un daño generado por responsabilidad ambiental, el Estado señala zonas de exclusión de actividades relacionadas con la explotación de canteras, carbón y minería. De forma concreta, la Corte Constitucional

\footnotetext{
${ }^{1}$ En este punto, es importante señalar lo que ha indicado la Corte Constitucional en relación con la consulta previa, que se debe agotar con las comunidades que habitan lugares de Colombia que pueden ser explotados económicamente. "En reciente pronunciamiento, esta corporación declaró la inexequibilidad de la Ley 1518 de 2012, que aprobó el 'Convenio Internacional para la Protección de Obtenciones Vegetales'. Entonces, se consideró que ha debido realizarse la consulta previa a las comunidades indígenas y afrocolombianas, toda vez que dicho convenio regulaba directamente aspectos sustanciales que conciernen a estas comunidades, en calidad de obtentores de las especies vegetales cuya propiedad intelectual se protege, tales como los criterios para reconocer la calidad de obtentor, concesión del derecho, periodicidad, condiciones de protección, reglamentación económica y utilidad que reporta la mejora y ampliación de variedades vegetales, los cuales en buena parte se considera materia de conocimientos ancestrales de estos pueblos. La Corte concluyó que la imposición de restricciones propias de una patente sobre nuevas variedades vegetales, como las que consagra el Convenio Internacional para la Protección de las Obtenciones Vegetales de 1991, podrían significar una limitación al desarrollo natural de la biodiversidad producto de las condiciones étnicas, culturales y ecosistemas propios en donde habitan dichos pueblos. De allí que este tipo de tratados y sus leyes aprobatorias están sujetas a consulta previa a las comunidades étnicas y afrocolombianas, siempre que se regulen actividades que puedan afectarlas de manera directa, procedimiento que deberá surtirse antes del sometimiento a aprobación del Congreso de la República”.
} 
[...] aclaró que las zonas de exclusión de la actividad minera no se limitaban a las áreas que integran los parques nacionales naturales, los parques naturales de carácter regional y a las zonas de reserva forestal, sino que pueden existir otras declaradas con anterioridad o que se declaren en el futuro por la autoridad ambiental [...] Por lo tanto, las autoridades ambientales pueden declarar excluidos de la minería ecosistemas tales como los páramos, así no estén comprendidos en parques nacionales o regionales o en zonas de reserva forestal. En segundo lugar, el inciso segundo fue declarado exequible en el entendido que el deber de colaboración de la autoridad minera no condiciona el ejercicio de la competencia de la autoridad ambiental (Corte Constitucional, Sent. C-443/09) (cfr. Corte Constitucional, Sent. C-339/02).

Lo consagrado por la Constitución Política de Colombia genera tensiones. Lo precedente, por la necesidad de exploración y explotación por parte del Estado o particulares de recursos naturales renovables y no renovables; actividades que pueden generar responsabilidad ambiental y son objeto de aseguramiento a través del seguro de responsabilidad civil, destinado al tomador o asegurado virtual dañador del medio ambiente. Póliza que tiene como objetivo indemnizar los perjuicios causados a las víctimas por la alteración del medio ambiente, y no la salvaguarda de este.

\subsection{La tensión existente entre la protección del medio ambiente y la explotación económica de los recursos naturales}

La problemática generada en el medio ambiente se incrementa en los países en vía de desarrollo, donde sus habitantes reclaman una existencia humana digna, con alimentación adecuada, educación y un servicio de salud eficiente. De ahí la necesidad de dirigir los esfuerzos de los países desarrollados para generar equidad y salvaguardar el medio ambiente, principalmente cuando el proceso de industrialización y el desarrollo tecnológico pueden desequilibrar el ambiente sano (onu, 1972). Por este hecho, el sector industrial debe tomar las medidas necesarias para prevenir los daños a las personas, y no únicamente indemnizar los perjuicios a través de compañías aseguradoras, a quienes se les traslada el riesgo inherente a la actividad fabril. 
Es más rentable explotar los recursos naturales y pagar el daño ambiental con capitales propios o por medio del sistema de seguros, lo que no puede ser una estrategia económica válida. El concepto de calidad de vida desde lo económico-cuantitativo no justifica la explotación y degradación del medio ambiente, sino que debe concentrarse en la neutralización de las diferencias sociales existentes en la actualidad. De la citada degradación emerge el derecho ambiental, que tiene un carácter preventivo, sistémico, interdisciplinario y transversal, el cual propende por la distribución equitativa del costo-beneficio, con una propuesta integradora, dinámica y diversa (Jaquenod de Zsögön, 2004, p. 198). ${ }^{2}$ La interdisciplinariedad se observa en el carácter preventivo del derecho ambiental, los tratados, los convenios y todas las conferencias relacionadas con la función de regulación y sanción de conductas, para reprimirlas cuando estas atenten contra el medio ambiente.

\subsubsection{La Conferencia de Estocolmo y la protección del medio humano}

La Conferencia de las Naciones Unidas sobre el Medio Humano, más conocida como 'Conferencia de Estocolmo', se instituyó en un evento de relevancia para discutir temas relacionados con el medio ambiente y la incorporación de una política ambiental en el ámbito internacional. El citado evento fue el primero en orientar la agenda ambiental de la onu y de la comunidad internacional. No obstante, fue imposible la consecución de acuerdos relacionados con la protección de los bosques, la población, la regulación de la energía y de los patrones de producción y consumo (Cherni, 2006, p. 4); lo precedente, por la generación de tensiones entre el derecho a explotar los recursos naturales y la protección del medio ambiente.

\footnotetext{
2 "Lo sistémico alude a que la concepción, dinámica, dimensión y normas en general, están al servicio de la regulación de los distintos elementos, fenómenos y procesos naturales, sociales y culturales que componen el ambiente. Un sistema se caracteriza por un conjunto de elementos relacionados entre sí y por el carácter de totalidad del conjunto". "Es interdisciplinario y transversal, porque en él se yuxtapone una amplia gama de disciplinas más o menos relacionadas. Esta interdisciplinariedad se articula dentro de un marco de importación de conceptos, procedimientos, metodologías, aplicándose técnicas de un campo y adaptándolas a otros. Un auténtico derecho ambiental abordará las diferentes situaciones ambientales desde la interdisciplinariedad, protegiendo el ambiente desde un enfoque con amplias bases de colaboración científica, captando la diversidad de ciencias y de ramas jurídicas" (Jaquenod de Zsögön, 2004, p. 198).
} 


\subsubsection{Los principios que orientan la protección del medio ambiente en Colombia}

El Estado colombiano profiere normas que buscan prevenir y controlar la contaminación ambiental, y adicionalmente mejorar y conservar los recursos naturales. Así mismo, la política dirigida a la protección del medio ambiente en Colombia incorpora los principios universales relacionados a continuación: en primer lugar, se debe priorizar el desarrollo sostenible; en segundo lugar, se revela que la biodiversidad del país es considerada patrimonio nacional y de interés global; $y$, por último, se dispone que la vida saludable y productiva del ser humano es un derecho que debe ser salvaguardado. Igualmente, se establece que

[...] 4. Las zonas de páramos, subpáramos, los nacimientos de agua y las zonas de recarga de acuíferos serán objeto de protección especial.5. En la utilización de los recursos hídricos, el consumo humano tendrá prioridad sobre cualquier otro uso. 6. La formulación de las políticas ambientales tendrá en cuenta el resultado del proceso de investigación científica. No obstante, las autoridades ambientales y los particulares darán aplicación al principio de precaución conforme al cual, cuando exista peligro de daño grave e irreversible, la falta de certeza científica absoluta no deberá utilizarse como razón para postergar la adopción de medidas eficaces para impedir la degradación del medio ambiente. 7. El Estado fomentará la incorporación de los costos ambientales y el uso de instrumentos económicos para la prevención, corrección y restauración del deterioro ambiental y para la conservación de los recursos naturales renovables (Chavarro, 2010, p. 8). ${ }^{3}$

El Estado previene, corrige y restaura el medio ambiente alterado, porque es patrimonio común, y tanto aquel como los particulares están obligados a participar de forma activa en su conservación; medio ambiente que está

3 “[...] recursos naturales renovables, a saber: 1. La atmósfera y el espacio aéreo nacional. 2. Las aguas en cualquiera de sus estados. 3. La tierra, el suelo y el subsuelo. 4. La flora". "El Presidente de la República de Colombia, en ejercicio de las facultades extraordinarias conferidas por la Ley 23 de 1973 y previa consulta con las comisiones designadas por las cámaras legislativas y el Consejo de Estado, dicta el Código Nacional de Recursos Naturales Renovables y de Protección al Medio Ambiente" (Congreso de la República, Decreto 2811 de 1974). 
conformado por la atmósfera y los recursos naturales renovables. Los citados recursos tienen la facultad de regenerarse a través de procesos naturales, a menos que el ser humano y circunstancias externas no permitan la posibilidad de regeneración; es el caso de la caza de animales en vía de extinción, o la tala indiscriminada de árboles. Al mismo tiempo, "[... ] se consideran bienes contaminables el aire, el agua y el suelo" (Congreso de la República, Ley 23 de 1973, art. 30); 4 bienes que un seguro ecológico no puede proteger de manera integral, porque lo amparado es el patrimonio del asegurado, quien puede ser, por ejemplo, un transportador marítimo causante de responsabilidad ambiental.

\subsubsection{Safety Management Code y el transporte marítimo de personas y mercancías}

Existen diferentes tipos de transporte de mercancías y pasajeros que contaminan el medio ambiente por donde transitan: los transportes aéreo, terrestre, fluvial, lacustre, multimodal y marítimo, se reitera, son generadores de daño ambiental; para el último caso, la Organización Marítima Internacional ${ }^{5}$ instituye el denominado Safety Management Code, que regula los niveles de contaminación generada por las naves en su trayecto. Se dispone en el citado Code que el armador debe obtener la certificación con vigencia anual, documento que debe indicar el cumplimiento de las reglas establecidas para el transporte de pasajeros, tanqueros, químicos, granos, petróleo, entre otros (Narváez, 2000, p. 80). Transporte considerado una actividad peligrosa, que

\footnotetext{
${ }^{4}$ Por la cual se conceden facultades extraordinarias al Presidente de la República para expedir el Código de Recursos Naturales y Protección al Medio Ambiente y se dictan otras disposiciones.

${ }^{5}$ As a specialized agency of the United Nations, IMO is the global standard-setting authority for the safety, security and environmental performance of international shipping. Its main role is to create a regulatory framework for the shipping industry that is fair and effective, universally adopted and universally implemented [...] In other words, its role is to create a level playing-field so that ship operators cannot address their financial issues by simply cutting corners and compromising on safety, security and environmental performance. This approach also encourages innovation and efficiency [...] Shipping is a truly international industry, and it can only operate effectively if the regulations and standards are themselves agreed, adopted and implemented on an international basis. And IMO is the forum at which this process takes place". The International Maritime Organization is the United Nations specialized agency with responsibility for the safety and security of shipping and the prevention of marine pollution by ships. Recuperado de http://www.imo.org/About/Pages/Default. aspx
} 
debe contar con una póliza de responsabilidad civil contractual y extracontractual de carácter obligatorio.

El transporte de mercancías denominadas 'azarosas', es decir, combustibles, productos inflamables, entre otras, implica un peligro inminente, pero, por su naturaleza y características, generan un alto índice de rentabilidad para el transportador y el titular de las mercancías. Los siniestros de incendio, volcamiento, explosión, emisión radiactiva, entre otros, producen degradación del lugar donde ocurren, por esto, se requiere un transporte y almacenamiento con extremas medidas de seguridad (Mapfre, 2014). En suma, el contrato de transporte marítimo comporta riesgos inherentes a su actividad, porque en el trayecto o aun fuera de él pueden presentarse naufragios, averías y eventos adversos que producen daños ambientales sufragados por el asegurador. Ciertamente,

[...] las mayores catástrofes han sido siempre protagonizadas por grandes petroleros que, por diversas razones, han vertido miles de toneladas de petróleo al mar. Si bien en las primeras épocas de la navegación el seguro hacía referencia a la carga, al buque y al flete principalmente, y el principio de libertad de los mares ha evolucionado y sufrido una serie de importantes limitaciones. En 1609 el holandés Grotius fue el primero en proclamar la libertad de los mares, quedando limitadas las aguas territoriales a unas tres millas marinas de la costa. La cobertura de los seguros marítimos se ha ido extendiendo a los daños ambientales en cuanto a los recursos naturales per se, a la recuperación del área afectada y a la indemnización de las víctimas (Jaquenod de Zsögön, 2004, p. 233).

Finalmente, la degradación del ecosistema marítimo y forestal afecta significativamente la supervivencia normal de las especies. Los animales dependen del mar, el bosque y las plantas, que, al ser deforestadas, alteran el hábitat, y, por ende, sus habitantes tienen a desintegrarse por la modificación de los microclimas existentes, la aparición de tiempo seco y la proliferación de plagas (Jaquenod de Zsögön, 2004, p. 237). Puede existir un código de seguridad marítimo y un seguro ecológico que cubra los perjuicios generados por la responsabilidad ambiental, pero, si al hacer la ponderación entre la economía y la protección 
del medio ambiente prima la primera, las normas reglas y principios que se expidan para la protección del medio ambiente son insignificantes.

\subsection{El régimen de responsabilidad ambiental aplicado en Colombia}

Colombia es un país ubicado en Sudamérica, con abundante biodiversidad; la biodiversidad está relacionada con la variedad de especies que hacen presencia en una dimensión espacio-temporal, y que, a su vez, interactúan, se integran, se adaptan y evolucionan en un medio ambiente específico (Ñique, 2010, p. 3). No obstante, se evidencia, en principio, la ausencia de programas educativos y políticas de Estado que permitan la protección de las especies existentes en el país, y la falta de sanciones ejemplarizantes que modifiquen la conducta de quien degrada el medio ambiente. Sanciones donde se aplique el régimen objetivo de responsabilidad con dimensión social, es decir, con la incorporación de la presunción de responsabilidad derivada del daño ambiental. ${ }^{6}$

\subsubsection{La Revolución Industrial y el medio ambiente}

La temática relacionada con el medio ambiente surge en la década de los setenta por el acelerado crecimiento de la economía, sobre todo en los países industrializados. La expansión de la industria, la actividad minera y la economía siempre ligada con el desarrollo del hombre (Jaquenod de Zsögön, 2004, p. 241 $)^{7}$ generó problemas ambientales que se analizan de forma permanente por la comunidad internacional y por los Estados involucrados en el daño,

\footnotetext{
${ }^{6}$ Así mismo, Colombia es un país ubicado en el extremo nororiental de América del Sur, tiene costas en los océanos Pacífico y Atlántico, con dos períodos de lluvia: la primera de abril a junio y la segunda de agosto a noviembre. Este país comparte fronteras con Ecuador, Perú, Venezuela, Brasil, Perú y Panamá, así como tiene límites marítimos con República Dominicana, Haití, Jamaica, Nicaragua, Costa Rica y Honduras. Este hecho hace que se generen conflictos con los países vecinos; un ejemplo de lo afirmado es el conflicto entre Ecuador y Colombia por el uso de glifosato, herbicida utilizado para el control de cultivos ilícitos.

7 "Los minerales han estado siempre ligados a la evolución de la humanidad, ello al punto que a las diferentes etapas prehistóricas se las identifica con nombres de distintos minerales, y aunque éstas no comenzaron al mismo tiempo en todos los continentes, se las conoce como Edad de Piedra, Edad de Bronce, Edad de Cobre, Edad de Hierro, Edad del Petróleo. En la Edad de Piedra puede que el ser humano ya hubiera descubierto el carbón; pero es recién en el siglo xvi, cuando a consecuencia de la desaparición de los bosques, se utiliza como fuente de energía" (Jaquenod de Zsögön, 2004, p. 241).
} 
quienes trasladan los riesgos de sus actividades a una compañía aseguradora. Empresa que expide en la actualidad el denominado seguro ecológico.

Adicionalmente, se evidencia que los avances tecnológicos y científicos fueron utilizados, en principio, para la industria bélica, y, posteriormente, fueron direccionados a la eficacia en la producción masiva de bienes y servicios públicos (Jankilevich, 2003, p. 5). Así mismo, la Revolución Industrial introdujo un cambio en la relación laboral, con la necesidad de suscribir el seguro de responsabilidad para empleadores, virtuales causantes de daños a los trabajadores. En suma,

las condiciones del trabajo van a constituir un ineludible soporte para los grupos de trabajadores hacinados en los centros fabriles y ciudades industriales de reivindicaciones, que se orientarán hacia unas demandas de las condiciones de vida más saludables y menos contaminadas. La degradada situación afectaba en mayor medida a cuyas condiciones agudización de los de vida eran penosas [sic]. Ha de admitirse que, en la Revolución Industrial, se han producido efectos negativos como la polución atmosférica y de las aguas, las enfermedades de los obreros contraídas en larguísimas jornadas de trabajo, la agudización de los antagonismos sociales y otras varias dedicadas al estudio de esta época histórica. En circunstancias concretas, a corto plazo, hubo cierta recesión en el nivel de vida de las gentes (Delfín, 2011, pp. 37-38). ${ }^{8}$

Al mismo tiempo, se puede afirmar que la estructuración del régimen objetivo de responsabilidad civil derivada de la contaminación ambiental surge de convenios internacionales donde se discutieron temas relacionados con la energía nuclear, la contaminación por hidrocarburos de aguas marinas,

\footnotetext{
8 "El humo oscureció los cielos de Manchester y Birmingham, y la vida en las ciudades se hizo más triste. Las pequeñas villas industriales, tales como Oldham o Bilston, cobraron un aspecto hostil; [...] Hubo también, según parece, una decadencia del gusto, tal como los mismos tipos de imprenta, empleados en los libros, que han de consultarse lo demuestra [...] Mucho se ha escrito sobre los efectos de la Revolución Industrial en los obreros. Gran parte de los historiadores,impresionados por el número de los que perecieron en su lucha contra la máquina, han declarado que los cambios técnicos trajeron poco más que miseria y pobreza"(Asthon, 1989, p. 89; Díaz, 2011,pp. 37-38).
} 
entre otros (Galvis, 1999). ${ }^{9}$ La aplicación de la responsabilidad civil objetiva, es decir, sin culpa, expresa las relaciones de intercambio de una sociedad individualista que busca la explotación y comercialización de bienes y servicios, causando daño al ambiente sano, instituido como un derecho humano. En suma, la responsabilidad por el hecho dañoso lícito o ilícito "[...] se consagra en función del individuo y de su capacidad como ente racional y autónomo para responder de sus actos cuando éstos lesionan, sea dolosa o culposamente, el derecho de otro" (Jaquenod de Zsögön, 2004, p. 229).

\subsection{El seguro ecológico}

La primera expresión del seguro ambiental o ecológico, como se le denomina en Colombia, se presenta en los Estados Unidos de Norteamérica en la década de los setenta, a través de la mencionada National Environmental Policy Act. ${ }^{10}$ El propósito de la citada norma era procurar el respeto del medio ambiente y el aseguramiento del riesgo ambiental por parte de las empresas con mayor desarrollo industrial, quienes se constituían en las tomadoras o aseguradas de la póliza de responsabilidad civil. Es importante advertir que los aseguradores no exigían garantías ${ }^{11}$ a sus clientes, porque el daño ambiental se consideraba un siniestro que no representaba mayores consecuencias para la compañía de seguros (Pinilla, 2003, pp. 157-179).

El riesgo que una vez exteriorizado se convierte en siniestro ambiental se encontraba incorporado en una cláusula adicional al seguro de daños patrimoniales, en el ramo de responsabilidad civil; riesgo derivado de la actividad

\footnotetext{
${ }^{9}$ Cabe anotar, además, que en Italia el Ministerio del Medio Ambiente fue creado por la Ley $8^{\mathrm{a}} \mathrm{de}$ 1986 y a ella se incorporaron disposiciones de responsabilidad por daños al medio ambiente. Alemania, por su parte, expidió en 1990 la Ley 10, para regular también la responsabilidad ambiental. Se establece entonces que, "en el mundo, la preocupación por estructurar un régimen de responsabilidad civil por contaminación ambiental data del año de 1960: el Convenio de París del 2Q de junio, en el que se incorporó un régimen para el sector de la energía nuclear, y la ley española del 29 de abril de 1964, que hizo viable la cobertura de riesgos nucleares reglamentada a través del decreto del 22 de junio, así lo corroboran; por su parte, el Convenio de Bruselas del 29 de noviembre de 1969, relativo a la contaminación por hidrocarburos de las aguas marinas, así lo demuestra. Francia incorporó una ley en este sentido en el año 1977, Italia lo hizo en 1980, Alemania en 1982, Holanda en 1984, Estados Unidos en 1985 y Dinamarca en 1992" (Galvis, 1999).

${ }^{10}$ Ley de Política Nacional Ambiental, expedida en 1969.

${ }^{11}$ Las garantías en favor del asegurador las constituyen la prenda, la hipoteca o, en su defecto, las obligaciones impuestas a cargo del tomador o asegurado, por ejemplo, la instalación de alarmas o la vigilancia armada.
} 
industrial, es decir, de naturaleza peligrosa donde se aplica la denominada teoría del riesgo. En síntesis,

la teoría del riesgo genera una tendencia, que se mantiene en todos los ámbitos del derecho (excepto el penal), hacia la consagración de la responsabilidad objetiva, que permite la reparación sin que pueda atribuirse una conducta antijurídica directa a quien resulta condenado, y se amplía el concepto, eliminando la condición del beneficio económico para incluir así todas las actividades peligrosas cualquiera sea la razón para que alguien las esté realizando. Pero hay más, se han identificado casos en que la ocurrencia del daño da lugar a la reparación, sin que exista la posibilidad de eximirse, tratando de desvirtuar el nexo o la culpa de la víctima, en lo que se denomina una responsabilidad objetiva plena (Medina, 2009, p. 165). ${ }^{12}$

El derecho comercial, y concretamente el derecho de seguros, sumado al derecho de daños con énfasis en responsabilidad ambiental y la aplicación del régimen objetivo con dimensión social, contribuye a garantizar los derechos a la verdad, a la justicia y a la reparación integral de las víctimas del daño al medio ambiente (Jaquenod de Zsögön, 2004, p. 229).13 De un lado, el legislador

${ }^{12}$ En Chile, “[...] no existe una póliza diseñada específicamente para cubrir la responsabilidad por daño ambiental, pero su cobertura opera a través de las antedichas cláusulas adicionales. Importante es hacer revisar lo contenido en la póliza de responsabilidad civil (conocida comúnmente como modelo suizo) y su cláusula de cobertura adicional de responsabilidad civil por contaminación asimilada de NMA 1685 (Lloyd's Non Marine Association), las que en la práctica asegurativa son las más utilizadas. No obstante, se debe advertir que, desde la vigencia de la póliza de responsabilidad antedicha, han sido aprobadas por la Superintendencia de Valores y Seguros otras pólizas de responsabilidad civil con su cláusula adicional de cobertura de responsabilidad civil por contaminación, las cuales son de escasa utilización y conocimiento en el mercado asegurador" (Cfr. poL 191086 Res. 236 del 31/12/1991. Compañía de Seguros Generales Euroamérica S.A. Póliza de responsabilidad civil. Modificada por Res. 44 de 27/03/1992. Cfr. caD 197010. Res. 211 del 17/07/1997. Asociación de Aseguradores de Chile A.G. Cobertura de responsabilidad civil por contaminación asimilada de NMA 1685. Lloyd's Non Marine Association. Cfr. Pol 197008. Res. 211 del 17/07/1997. Asociación de Aseguradores de Chile A.G. Póliza de responsabilidad civil. Cfr. cad 197009. Res. 211 del 17/07/1997. Asociación de Aseguradores de Chile A.G. Cobertura de responsabilidad civil por contaminación, adicional a:póliza de responsabilidad civil PoL 197008).

13 "La evolución del derecho comercial o mercantil ha sido paralela al desarrollo del comercio, en esta dinámica el derecho comercial o mercantil se va adaptando progresivamente y sin interrupción a las nuevas realidades y necesidades comerciales. La primera compilación de normas comerciales que se 
expide normas que integran los derechos civil y comercial, con el objeto de crear los seguros ecológicos que permiten cubrir los perjuicios patrimoniales y extrapatrimoniales de la víctima, causados por el daño al ambiente y a los recursos naturales (Congreso de la República de Colombia, Código Penal, 1999). De otro lado, el poder legislativo incorpora reformas al Código Penal en lo atinente a los delitos ambientales (Congreso de la República de Colombia, Código Penal, 1999, arts. 14-24)..$^{14}$

Así, el derecho penal consagra normas que protegen los recursos naturales, que son insustituibles y, por tal razón, se "[...] define ontológicamente la categoría del delito ambiental, puesto que sin lugar a duda constituye un delito que atenta contra las bases mismas de la vida, de la subsistencia del mundo orgánico, de la permanencia del mundo inorgánico y, globalmente, de la existencia de todos los seres"( Jaquenod de Zsögön, 2004, p. 230).

\subsubsection{Objetivo de la celebración de un contrato de seguro ecológico}

El seguro ecológico protege el patrimonio del tomador o asegurado, y garantiza el pago de la indemnización a la víctima de la responsabilidad ambiental, pero no previene que el daño se manifieste, es decir que el siniestro se realice. Por este motivo, es relevante adoptar medidas apropiadas para ser aplicadas en el ámbito nacional e internacional, tendientes a proteger de forma eficaz el medio ambiente (Rodríguez, Narran y Alonso, 1997, p. 7). La nombrada protección debe provenir del Estado, quien tiene la obligación, por una parte, de abstenerse de causar daños irreversibles al medio ambiente y, por otra, de adoptar las medidas necesarias y razonables para regular el comportamiento

\footnotetext{
conoce es la Lex Rhodia, la cual hace sólo referencia al derecho comercial o mercantil de la navegación. Esta fue confirmada por varios emperadores, así como en un Edicto de Antonino: 'Yo soy dueño del mundo entero, pero la mar está sometida a las leyes. Este negocio debe ser juzgado por la Ley Rodia, que se refiere al comercio marítimo, mientras esta ley no sea contraria a nuestras ordenanzas"(Jaquenod de Zsögön, 2004, p. 229).

${ }^{14}$ La norma expedida por el Congreso ha modificado normas relativas a las siguientes conductas consideradas como punibles: incendio, daño en obras de defensa común, provocación en inundación o derrumbe, tenencia, fabricación y tráfico de sustancias u objetos peligrosos. Así mismo, la norma crea nuevas conductas punibles con el objetivo de salvaguardar el medio ambiente, como las siguientes: ilícito aprovechamiento de recursos biológicos, invasión de áreas de especial importancia ecológica, explotación o exploración ilícita minera o petrolera, manejo ilícito de microorganismos nocivos, manejo ilícito de microorganismos nocivos, omisión de información, contaminación ambiental (cfr. Congreso de la República de Colombia, Código Penal, 1999, arts. 14-24).
} 
de las personas naturales y jurídicas, potenciales causantes de daños al ambiente. Por consiguiente, "[...] esta obligación implica el deber de los Estados de generar un sistema normativo que obligue a los particulares a no dañar el ambiente, así como de instituir políticas que permitan el control del cumplimiento de tales disposiciones" (Corte Constitucional, Sent. T-851/10).

En este orden de ideas, el objetivo de contratar un seguro ecológico es salvaguardar el patrimonio del tomador o asegurado, quien es potencial generador de daños en la explotación de recursos naturales o en actividades como el transporte. Es decir, el interés asegurado protegido no es el patrimonio de la víctima, sino del victimario contaminador del ambiente, sobre quien pueden recaer procesos judiciales donde se demanda la obligación de indemnizar los perjuicios causados a terceros. Se reitera que otro objetivo del seguro ecológico es garantizar la indemnización integral a cargo del asegurador por los perjuicios generados a la víctima del daño ambiental. Los perjuicios pueden ser originados por dos situaciones: la primera, por los daños al ambiente y a los recursos naturales para los efectos del seguro de responsabilidad civil extracontractual imputable al tomador o asegurado; y la segunda, en el evento de la afectación de los seguros de daños reales, originados en "[...] un hecho accidental, súbito e imprevisto de la acción de un tercero o por causas naturales" (Congreso de la República de Colombia, Código Penal, 1999).

\subsubsection{Características del seguro ecológico}

El seguro ecológico es un contrato consensual, donde impera la voluntad del tomador o asegurado y de la compañía de seguros, quienes celebran el acto jurídico de acuerdo con las condiciones generales y particulares establecidas en la póliza; acto jurídico caracterizado por ser bilateral y a la vez pluripersonal, porque actúan dos partes y una pluralidad de personas naturales o entes jurídicos, que convienen en la celebración del contrato; convención donde una parte traslada el riesgo a la compañía de seguros, a cambio del pago de una prima. El precio del seguro o prima hace del seguro un acuerdo oneroso y, a la vez, aleatorio, porque siempre el tomador está obligado a pagar el precio del seguro, pero no siempre la compañía tiene el deber de pagar el siniestro, a menos que este ocurra dentro de la vigencia del contrato; vigencia que hace que el contrato sea de ejecución tracto sucesiva, puesto que a cada instante el riesgo por daño ambiental está latente. 


\subsubsection{Clases de seguro ecológico}

Las clases de seguro ecológico en Colombia son dos: el obligatorio y el voluntario. Antes de hacer referencia a cada una de las clases del citado seguro, es importante señalar que las tendencias relacionadas con la protección de los recursos naturales iniciaron con la fundación del Club de Roma, ${ }^{15}$ creado con el objetivo de generar conciencia en las personas acerca del problema ecológico. El estudio realizado por la mencionada fundación evidencia que la base del inconveniente del daño ambiental es producto de la ignorancia de las personas acerca de temas relativos a la ecología y su papel en la Tierra, la relación con el medio ambiente y su cuidado. El ser humano prioriza sus necesidades, orientadas principalmente en "[...] la economía, la tecnología, los estilos de vida, y la misma política” (Gamboa, 2011, p. 3), dejando en un segundo plano la protección del medio ambiente. En este orden de ideas, se enfatiza que el seguro ecológico obligatorio o voluntario no protege el medio ambiente ni previene el daño ambiental, tal como se demuestra a continuación.

\subsubsection{El seguro ecológico obligatorio}

E1 legislador colombiano ha establecido un seguro ecológico con carácter obligatorio para quienes desarrollan actividades humanas que puedan generar daños al medio ambiente. Es una póliza que la norma exige en actividades donde es obligatoria la expedición de una licencia ambiental; esta es un documento público requerido por el Estado al proponente de un proyecto por la ejecución de una obra pública o la prestación de un servicio en favor del Estado (DAFP, 2011).16 El seguro ecológico obligatorio se puede 'homologar' con la

15 "E1 Club de Roma es una organización independiente sin ánimo de lucro. Su trabajo se centra en las principales causas que explican los retos y crisis que atraviesa el planeta en la actualidad: los conceptos actuales de crecimiento, desarrollo y globalización. El Club de Roma funciona como plataforma que congrega a académicos, científicos, políticos, hombres de negocios y funcionarios para diseñar, desarrollar y poner en marcha modelos de actuación eficaces para tratar numerosos asuntos de alcance mundial que se hayan relacionados, como la sustentabilidad medioambiental, el crecimiento económico , el consumos de recursos, la paz, la seguridad y la demografía mundial. La Secretaría General del Club se encuentra en Winterthur, Suiza”. Recuperado de http://www.clubofrome.org/?p=4773

16 "La Autoridad Nacional de Licencias Ambientales (ANLA) es la encargada de que los proyectos, obras o actividades sujetos de licenciamiento, permiso o trámite ambiental cumplan con la normativa ambiental, de tal manera que contribuyan al desarrollo sostenible ambiental del país [...]”. Funciones artículo 30, Decreto 3573: "La Autoridad Nacional de Licencias Ambientales (ANLA) cumplirá las siguientes funciones: [...]1. Otorgar o negar las licencias, permisos y trámites ambientales de competencia del Ministerio de Ambiente y Desarrollo Sostenible, de conformidad con la ley y los reglamentos [...] 
póliza de responsabilidad civil extracontractual que haya suscrito el tomador del seguro con la obligación de tramitar la licencia ambiental, y, por ende, no es obligatoria la suscripción del seguro ecológico. La 'homologación' es verificada por la autoridad ambiental respectiva, con el propósito de establecer “[...] que efectivamente tenga las coberturas y los montos asegurados adecuados" (Congreso de la República de Colombia, Código Penal, 1999, art. 3º).

En este orden de ideas, el legislador impone la obligación de la suscripción del seguro ecológico, porque el hombre es un ser que afecta permanentemente el medio ambiente. Por este hecho, nace lo que algunos tratadistas han denominado 'la ecología humana', que es la disciplina encargada de la recopilación, estudio e interpretación de la relación del ser humano en su entorno con el ecosistema del planeta. La citada relación no únicamente es enunciada, sino aplicada a "[...] la incidencia de factores que el hombre introduce, que apriorísticamente no sólo perturban la relación natural, sino que los enfrenta con factores de riesgo de vida" (Ghersi, 1995, pp. 110-111).

A su vez, la norma impone una multa a quien estando obligado se abstiene de contratar la póliza de seguro de responsabilidad civil, que ampara los riesgos al medio ambiente. Así mismo, es acreedora de la multa la persona natural o jurídica que haya suscrito el seguro ecológico pero que este carezca

2. Realizar el seguimiento de las licencias, permisos y trámites ambientales [...] 3. Administrar el Sistema de Licencias, Permisos y Trámites Ambientales (siLA) y Ventanilla Integral de Trámites Ambientales en Línea (Vital) [...] 4. Velar porque se surtan los mecanismos de participación ciudadana de que trata la ley relativos a licencias, permisos y trámites ambientales [...] 5. Implementar estrategias dirigidas al cuidado, custodia y correcto manejo de la información de los expedientes de licencias, permisos y trámites ambientales [...] 6. Apoyar la elaboración de la reglamentación en materia ambiental [...] 7. Adelantar y culminar el procedimiento de investigación, preventivo y sancionatorio en materia ambiental, de acuerdo con lo dispuesto en la Ley 1333 de 2009 o la norma que la modifique o sustituya [...] 8. Adelantar los cobros coactivos de las sumas que le sean adeudadas a la Autoridad Nacional de Licencias Ambientales (ANLA) por todos los conceptos que procedan [...] 9. Ordenar la suspensión de los trabajos o actividades, en los casos en los que el Ministerio de Ambiente y Desarrollo Sostenible haga uso del ejercicio discrecional y selectivo sobre los asuntos asignados a las Corporaciones Autónomas Regionales [...] 10. Aprobar los actos administrativos de licencias ambientales para explotaciones mineras y de construcción de infraestructura vial y los permisos y concesiones de aprovechamiento forestal de que tratan los artículos 34, 35 y 39 de la Ley 99 de 1993 [...] 11. Dirimir los conflictos de competencia cuando el proyecto, obra o actividad sujeto a licencia o permiso ambiental se desarrolle en jurisdicción de dos o más autoridades ambientales [...] 12. Desarrollar la política de gestión de información requerida para el cumplimiento de su objeto [...] 13. Asumir la representación judicial y extrajudicial de la nación en los asuntos de su competencia [...] 14. Las demás funciones que le asigne la ley" (Departamento Administrativo de la Función Pública, 2011). 
de vigencia o del amparo requerido por la norma. En síntesis, “[...] quien estando obligado a contratar la póliza ecológica y no contare con ella o no estuviese vigente, al momento de la ocurrencia del daño, podrá ser multado por la respectiva autoridad ambiental hasta por el equivalente a la mitad del costo total del daño causado" (Congreso de la República de Colombia, Código Penal, 1999, art. 11).

\subsubsection{Seguro ecológico voluntario}

En principio, es importante indicar que el derecho agrario ha sido catalogado desde sus orígenes como un derecho de naturaleza social, que busca transformar la estructura agraria nacional de carácter latifundista a minifundista, pero con un alto nivel de eficacia. El nombrado derecho agrario trata de modificar un sistema de relación 'hombre-hombre', es decir, un vínculo netamente social y económico, en una relación 'ser humano-naturaleza'. La primera relación tiene un régimen de apropiación del suelo y los recursos naturales, gobernado "[...] por la injusticia social y la ineficiente e irracional explotación de los factores de producción” (Jaquenod de Zsögön, 2004,p. 35). En las actividades realizadas en el citado régimen de apropiación, se generan riesgos que son trasladados de manera voluntaria por el potencial dañador a una compañía aseguradora a cambio del pago de una prima.

En Colombia, es viable la celebración de un contrato de seguro ecológico de forma voluntaria, al igual que en el continente europeo, donde la póliza se manifiesta, de un lado, desde el seguro de daños reales, que incluye incendio y terremoto, por ejemplo, y, de otro lado, a través del seguro de daños patrimoniales de responsabilidad civil de tipo contractual o extracontractual, la última derivada principalmente de accidentes nucleares (Pinilla, 2003, pp. 157-179). Así las cosas, el seguro ecológico de suscripción voluntaria lo puede contratar un particular o una entidad oficial o privada, con el objetivo de amparar los perjuicios económicos generados por el daño ecológico a sus bienes e intereses patrimoniales. Para que exista cobertura, el daño debe ser "[...] producido por un hecho accidental, súbito e imprevisto, por la acción de terceros o por causas naturales" (Congreso de la República de Colombia, Código Penal, 1999, art. 4º).

En suma, el seguro ecológico voluntario no procura la protección de todas las especies que hacen parte del ecosistema, conformado por la flora, la fauna, el aire, el suelo y el agua, entre otros, que se incorporan de forma armónica 
en el medio físico donde se desarrollan; se evidencia que todas las especies deben ser protegidas y no únicamente el género humano (Narváez, 2000, p. 80), quien tiene la potestad de asegurar su patrimonio contratando un seguro ambiental o ecológico. Así, el seguro obligatorio se derivada de las licencias ambientales, mientras que el voluntario tiene un carácter potestativo.

\subsubsection{Elementos esenciales del seguro ecológico}

E1 Estado tiene la obligación de realizar acciones positivas para facilitar, promover y proporcionar las medidas legislativas necesarias para la regulación del seguro ecológico, y también establecer los lineamientos administrativos de orden presupuestal y judicial que posibiliten a las personas y comunidades ejercitar el derecho al medio ambiente sano. Al mismo tiempo, le corresponde al Estado "[...] adoptar medidas para que se difunda información adecuada sobre la conservación del ambiente, su protección y los métodos para reducir la contaminación ambiental" (Corte Constitucional, Sent. C-851/10). Es evidente que el propósito del seguro ecológico no es la protección del medio ambiente, sino la salvaguarda del patrimonio de quien contamina y causa un daño. Seguro ecológico que tiene cuatro elementos esenciales: el interés asegurable, el riesgo asegurable, la prima y la obligación condicional del asegurador.

\subsubsection{El interés asegurable}

En el seguro ecológico, tiene interés asegurable el tomador o asegurado que, por ejemplo, deforesta y erosiona la tierra por la inadecuada explotación de los recursos naturales, es decir, quien genera un daño ambiental que puede ser demandado ante las autoridades, comprometiendo de esta manera su patrimonio. Este hecho debe generar conciencia sobre la importancia de la protección de la diversidad biológica, necesaria para la evolución y la preservación de la vida en la biosfera (onU, 1993). ${ }^{17} \mathrm{Al}$ no cuidar de la mencionada

17 "Los recursos biológicos de la Tierra son fundamentales para el desarrollo económico y social de la humanidad. Como consecuencia, existe un reconocimiento cada vez mayor de la diversidad biológica como bien mundial de valor inestimable para la supervivencia de las generaciones presentes y futuras. Al mismo tiempo la amenaza que pesa actualmente sobre las especies y los ecosistemas nunca ha sido tan grave. En efecto, la extinción de especies causada por las actividades del hombre continúa a un ritmo alarmante [...] En respuesta a ello, el Programa de las Naciones Unidas para el Medio Ambiente (PNUMA) convocó a un grupo especial de expertos sobre la diversidad biológica en noviembre de 1988, con el objeto de explorar la necesidad de un convenio internacional sobre la diversidad biológica. Poco tiempo después, en mayo de 1989, el PNUMA estableció el grupo de trabajo ad hoc de expertos jurídicos 
diversidad, se genera un cambio climático que lesiona los intereses de los seres que interactúan en el ecosistema.

Se entiende por cambio climático la serie de transformaciones producidas en el clima de la Tierra que impactan los ecosistemas, la vida en general y la humana en particular, lo que constituye un problema ambiental de gran relevancia en la actualidad, por "[...] la pérdida de la biodiversidad y el 'agujero’ de ozono. Los inconvenientes generados por el cambio climático están interrelacionados y ejercen sinergias entre ellos, se atribuye al aumento de la temperatura provocado por el ser humano la principal causa del cambio climático" (Tommasino y Foladori, 2006, p. 5).

\subsubsection{El riesgo asegurable}

Las empresas o personas naturales que en el ejercicio de su actividad puedan generar daño a una persona tienen interés asegurable, porque este seguro de daños reales y patrimoniales salvaguarda el patrimonio del potencial dañador ante la ocurrencia de un siniestro. Para efectos de la responsabilidad ambiental y el seguro ecológico, el riesgo es el hecho incierto que no depende de la voluntad del tomador o asegurado potencial generador de un daño ambiental, ni del beneficiario del seguro, es decir, la víctima a quien la aludida responsabilidad le genera perjuicios.

Además, la aplicación del régimen de responsabilidad objetivo con dimensión social incorporado en la responsabilidad ambiental se evidencia con la expedición de la Comprehensive Environmental Response Compensation and Liability Act o Cercla, donde se instituyen tres aspectos principales: la responsabilidad, la compensación a las víctimas de contaminación ambiental y la recuperación del ambiente de la zona afectada (Pinilla, 2003,pp. 157-179). ${ }^{18}$ Esta norma crea un impuesto a cargo de la industria petrolera y de productos

y técnicos para preparar un instrumento jurídico internacional para la conservación y la utilización sostenible de la diversidad biológica. Los expertos debieron tomar en consideración 'la necesidad de compartir los costos y los beneficios entre los países desarrollados y los países en desarrollo', así como 'los medios y la modalidad para apoyar las innovaciones de las comunidades locales" (onu, 1993) (Cfr. http://www.cbd.int/history/default.shtml).

18 Anteriores a la Cercla, se promulgaron leyes que sectorialmente establecieron el sistema de responsabilidad objetiva, tales como la Clean Air Act en 1970, la Clean Water Act en 1977, la Resource Conservative and Recovery Act en 1976, que regula el tratamiento de los desechos sólidos y peligrosos (Pinilla, 2003, pp. 157-179). 
químicos, y otorga plenas facultades a la autoridades para contrarrestar las “[... ] amenazas de escape de sustancias peligrosas que podrían poner en peligro la salud pública o el ambiente" (Agencia de Autoridad Ambiental de los Estados Unidos, 1986)..$^{19}$

\subsubsection{La prima}

La prima en el seguro ecológico es el precio del seguro, que debe ser proporcional al riesgo trasladado por el tomador a la compañía aseguradora. La responsabilidad ambiental está ubicada en el régimen objetivo de responsabilidad, es decir, en la dimensión social del riesgo, razón por la cual el monto de la prima es considerablemente alto. Así mismo, empieza a incorporarse en el vocabulario de las personas la expresión "la era atómica", relacionada con las fuentes de energía que serán utilizadas en el futuro, y el nacimiento de las centrales nucleares, donde existen numerosos siniestros generadores de un daño (González, 2012, p. 299), ${ }^{20}$ denominados 'accidentes nucleares'; accidentes donde es aplicada la mencionada teoría del riesgo con dimensión social, con el propósito de salvaguardar los derechos de las víctimas de daños nucleares.

Por ende, el siniestro relacionado con un accidente nuclear es un hecho que origina daños que provienen de las propiedades radiactivas, tóxicas, explosivas o peligrosas originadas por "[...] combustibles nucleares o productos o desechos radiactivos, o de las radiaciones ionizantes emitidas por otra fuente cualquiera de radiaciones que se encuentre en una instalación nuclear"

${ }_{19}$ Recuperado de http://www.epa.gov/superfund/spanish/descripcion_cercla.htm. La Cercla “[...] establece prohibiciones y requisitos para sitios con desperdicios peligrosos que están cerrados y abandonados; [...] provee responsabilidad a las personas responsables de emitir los desperdicios peligrosos en estos sitios; y [...] estableció un fondo de fideicomiso para proveer limpieza, mejora o restauración cuando el grupo o la persona potencialmente responsable no puede ser identificado".

20 "Se han producido dos accidentes con consecuencias radiológicas importantes en centrales nucleares, el de Chernobyl y el de Fukushima Daiichi, además de un accidente sin consecuencias radiológicas, el de la central de Three Mile Islands. Todos estos accidentes han recibido amplia publicidad. Sin embargo, ha pasado casi inadvertido que han tenido lugar más de 100 accidentes con fuentes industriales y médicas, especialmente con las denominadas fuentes 'huérfanas' (es decir, no sujetas a los controles reglamentarios), que han ocasionado lesiones a trabajadores y a la población. También han ocurrido accidentes durante los usos médicos de las radiaciones, casi siempre por error humano o mecánico durante la radioterapia. Aunque se sabe que los accidentes relacionados con fuentes huérfanas y los usos médicos de las radiaciones se han vuelto más frecuentes, es probable que las cifras actuales de las estimaciones reflejen niveles inferiores, o posiblemente muy inferiores, a los reales, debido a que los datos son incompletos" (González, 2012, p. 299). 
(Convención Internacional de París, 1960). En la responsabilidad causada al medio ambiente, se presume la responsabilidad del tomador o asegurado y, por esta razón, el valor de la prima, elemento esencial del seguro ecológico, es considerablemente elevado, porque los eximentes de responsabilidad a favor del victimario asegurado son limitados.

\subsubsection{La obligación condicional del asegurador}

La obligación del asegurador es un elemento esencial del seguro, sumado al interés asegurable, la prima y el riesgo asegurable. Es relevante indicar que el seguro ecológico está regulado por normas de carácter mercantil, lo que indica que el asegurador está obligado a pagar el siniestro, de acuerdo con lo establecido en el contrato. De esta manera, para determinar el daño ecológico generado por una persona natural o empresa, "la respectiva autoridad ambiental previa solicitud del interesado podrá certificar sobre la ocurrencia y la cuantía del siniestro, mediante acto administrativo debidamente motivado. El dictamen podrá servir de fundamento para la reclamación ante el asegurador, o en el proceso judicial que eventualmente se adelante" (Congreso de la República de Colombia, Código Penal, 1999, art. 6º. Por ende, el documento que certifique lo señalado con anterioridad es una prueba documental declarativa importante en el proceso extrajudicial o judicial en contra de la compañía de seguros; empresa que paga el siniestro conforme con las condiciones establecidas en la póliza.

Algunas compañías son renuentes a cubrir los riesgos desconocidos o con índices de siniestralidad existentes, y, por esta razón, imponen primas con valor significativo. En suma, las “[ ... ] primas en materia de seguros de responsabilidad ambiental suelen aumentar sustancialmente debido al grado superior de incertidumbre que existe" (Jaquenod de Zsögön, 2004, p. 397).21 Adicionalmente,

\footnotetext{
${ }^{21}$ En materia de responsabilidad civil e indemnización por daños al ambiente, existen importantes documentos, tales como el "Convenio de París (1960) sobre responsabilidad civil en el campo de la energía nuclear, Convenio de Bruselas (1963) por el que se establece un sistema complementario de indemnización por los daños causados por incidentes nucleares, Convenio de Viena (1963) sobre responsabilidad civil por daños nucleares, Convenio Internacional de Bruselas (1969) sobre responsabilidad civil por daños causados por la contaminación de las aguas del mar por hidrocarburos, Convenio de Bruselas (1971) sobre constitución de un fondo internacional de indemnización de daños causados por la contaminación de hidrocarburos, Convenio de Londres (1977) sobre responsabilidad civil por los daños de contaminación por hidrocarburos resultantes de la exploración y explotación de los recursos minerales de los fondos marinos, Convenio de Bruselas (1971) relativo a la responsabilidad civil en la esfera del transporte marítimo de materiales nucleares, Convenio de Ginebra (1989) sobre
} 
se indica en la norma que la prescripción extintiva o liberatoria derivada del contrato de seguro es de dos años, establecidos de la siguiente manera: la prescripción ordinaria es de dos años y la extraordinaria de cinco años (Congreso de la República de Colombia, Código Penal, 1999, art.90).22 La compañía aseguradora no se obliga a pagar la indemnización establecida en la póliza en el evento de operar la prescripción derivada de daños patrimoniales por responsabilidad civil. Es decir, la 'objeción' de pago del siniestro opera porque se extinguió la obligación por el transcurso del tiempo.

La víctima del hecho dañoso en materia ambiental cuenta con cinco años para ejercer su derecho a demandar en acción directa al asegurador, y, de no hacerlo, pierde la oportunidad de legitimar por activa a la compañía de seguros, y demandarla en un solo proceso. En concreto, la norma señala que "en el seguro de responsabilidad civil los damnificados tienen acción directa contra el asegurador. Para acreditar su derecho ante el asegurador de acuerdo con el artículo 1077, la víctima en ejercicio de la acción directa podrá en un solo proceso, demostrar la responsabilidad del asegurado y demandar la indemnización del asegurador" (Código de Comercio, art. 1133).

\subsection{Intervinientes en el seguro ecológico}

En el seguro ecológico, intervienen diferentes actores en calidad de partes, intermediarios, reaseguradores, ajustadores de seguros, actuarios, así como el beneficiario, quien es la víctima directa o indirecta del perjuicio generado.

\subsubsection{Las partes}

Son partes del seguro ecológico el tomador o asegurado y el asegurador, quien es persona jurídica, sociedad anónima, con un objeto social exclusivo y excluyente, es decir, producir seguros y comercializarlos de forma directa por medio de los intermediarios de seguros. Se aclara que el beneficiario del seguro ecológico obligatorio es interviniente y no parte en la póliza.

responsabilidad civil por daños causados durante el transporte de mercancías peligrosas por carretera, ferrocarril y buques de navegación interior" (Jaquenod de Zsögön, 2004, p. 397).

${ }^{22}$ La norma establece que "los términos de prescripción para las acciones que se derivan del contrato de seguro, contenidos en los artículos 1081 y 1131 del Código de Comercio o las normas que lo sustituyan o lo modifiquen, se hacen extensivas a los seguros ecológicos y se contarán desde el momento en que se tenga conocimiento del daño durante la vigencia de la respectiva póliza" (Congreso de la República de Colombia, Código Penal, 1999, art. 9º). 


\subsubsection{El tomador o asegurado}

El deterioro ambiental generado por el tomador o asegurado de la póliza es un hecho recurrente en Colombia. Nación con uno de los mayores índices de biodiversidad, y, a su vez, con un alto grado de detrimento ambiental producido por la extracción de minerales preciosos; extracción de oro, por ejemplo, donde son utilizados tóxicos que producen daño al suelo y a las fuentes hídricas aledañas a la explotación de los recursos naturales (Рві Colombia, 2011, p. 6). Es factible que la empresa o persona que realiza la actividad minera haya suscrito un seguro ecológico a través del cual la compañía de seguros cancela los perjuicios generados a la víctima en la actividad minera.

No obstante, si el valor amparado o límite de indemnización establecido entre el asegurador y el tomador no cubre la cuantía de los perjuicios producidos por el daño, "[...] quien fuere causante del hecho deberá responder por el monto de todos los daños y perjuicios que se hubieren producido en exceso de las sumas aseguradas en la póliza" (Congreso de la República de Colombia, Código Penal, 1999, art. 9º). Es evidente que las Naciones Unidas y lo consagrado por los principios del derecho internacional señalan que todos los Estados tienen el derecho de explotar y aprovechar sus recursos; sin embargo, si en los referidos procesos se generan daños por no acatar las políticas ambientales existentes en cada país, la compañía de seguros o el victimario tienen que garantizar el derecho humano y fundamental a la reparación integral a las víctimas.

Se insiste en que el Estado tiene el derecho a la exploración de los recursos naturales, pero tiene a su vez la obligación de inspeccionar, vigilar y controlar que las actividades desarrolladas dentro del país no causen daño al medio ambiente interno o externo, es decir, al de otro Estado vecino (Geary, 2006, p. 10). ${ }^{23}$ En el evento de exteriorizarse el riesgo asegurado, es decir,

\footnotetext{
${ }^{23} \mathrm{El}$ conflicto entre Argentina y Uruguay es un ejemplo de contaminación ambiental que traspasa la jurisdicción local. "El caso de las plantas de celulosa sobre la margen izquierda del río Uruguay podría ser leído como un conflicto diplomático, donde los reclamos entre los gobiernos de Argentina y Uruguay se deben a diferencias producidas en relación al uso del río como un bien público compartido. Sin embargo, a partir del conflicto trasciende que es un problema antiguo mucho más complejo, atravesado por cuestiones ambientales, que lleva más de tres años, donde gobiernos, vecinos organizados, grupos de estudiosos, técnicos y expertos vienen discutiendo y construyendo estrategias con resultados aún inciertos. E1 núcleo de la discusión radica en identificar, definir y argumentar la viabilidad ambiental y el riesgo del emprendimiento. Es decir, si el proyecto - ya avanzado, y cuya magnitud debe enfatizarse - pone en riesgo la salud y las actividades productivas de la población" (Geary, 2006, p. 10).
} 
causar daño al Estado o a terceros víctimas del hecho contaminante, “[...] el asegurado deberá dar aviso inmediato, por escrito, a la autoridad ambiental respectiva y al asegurador sobre el acaecimiento del daño" (Congreso de la República de Colombia, Código Penal, 1999, art. 9º). Al incumplirse con el reporte del daño antes indicado, la autoridad ambiental impondrá las multas establecidas por la norma (Congreso de la República de Colombia, Código Penal, 1999, art. 9o).24

\subsubsection{E1 asegurador}

El asegurador es la persona jurídica que 'produce' el seguro ecológico y lo comercializa de manera directa, o a través de los intermediarios de seguros. El Estado colombiano tiene a cargo las funciones de inspección, vigilancia y control de las compañías de seguros, por medio de la Superintendencia Financiera de Colombia; Estado que direcciona la economía nacional y regula los productos y servicios públicos ofrecidos, con el objetivo de mejorar la calidad de vida y la preservación del medio ambiente, que está en continuo riesgo de ser dañado (Constitución Política, 2013, art. 334). ${ }^{25}$ El riesgo de contaminación ambiental es catalogado como un hecho incierto que puede ser trasladado a una compañía aseguradora que tiene un objeto social exclusivo y excluyente, es

${ }^{24}$ La norma señala lo siguiente: "Quien estando obligado a reportar el daño y no lo hiciere oportunamente será multado por la respectiva autoridad ambiental hasta por el equivalente a cien (100) salarios mínimos mensuales legales vigentes, o a quinientos (500) salarios mínimos mensuales legales vigentes, si la circunstancia del reporte o su tardanza hubiere hecho más gravosas las consecuencias del daño" (Congreso de la República de Colombia, Código Penal, 1999, art. 9).

${ }^{25}$ Es relevante, en esta parte del texto, hacer alusión al Estado social de derecho. En este sentido, “[...] el principio del ESDD impone la protección de los derechos constitucionales desde una perspectiva fáctica, esto es, comprometida con la satisfacción de los intereses de los grupos sociales menos favorecidos, a través de una relación de dependencia entre la ciudadanía plena y el acceso efectivo a las garantías y libertades. En ese orden de ideas, son indiscutibles las fórmulas de intervención del Estado en la economía que, sujetadas en todo caso a criterios de razonabilidad y proporcionalidad, tengan por objeto lograr la igualdad de oportunidades y la distribución equitativa de los beneficios del desarrollo. No de otra manera debe interpretarse el artículo 334 c.P., cuando prescribe que esa intervención se justifica en cuanto tiene como finalidad la racionalización de la economía con el fin de conseguir el mejoramiento de la calidad de vida de los habitantes, la mencionada distribución equitativa y la preservación de un ambiente sano. Incluso, la misma fórmula constitucional de intervención del Estado en la economía reafirma el carácter nodal de la igualdad material, cuando determina que esa tarea se realizará con mayor énfasis cuando se trate de dar pleno empleo a los recursos humanos y asegurar que todas las personas, en especial las de menores ingresos, tengan acceso efectivo a los bienes y servicios básicos" (Corte Constitucional, Sent. C-288/12). 
decir, su única actividad mercantil es la de producir seguros y comercializarlos de manera directa o a través del agente, la agencia o el corredor de seguros. La compañía aseguradora es la acreedora de una prima o costo del seguro, que está a cargo del tomador o asegurado, quien tiene la obligación positiva de dar, esto es, pagar el valor respectivo por el traslado del riesgo.

\subsubsection{El beneficiario del seguro}

Las víctimas del daño ambiental tienen tres derechos fundamentales que deben ser protegidos por el Estado: el derecho a la verdad, a la justicia y a la reparación integral. El legislador ha señalado unos elementos que configuran el concepto de reparación integral, y no únicamente la indemnización pecuniaria a cargo del responsable del daño ambiental, “[... ] sino cualesquiera otras expresiones que contengan la verdad y la justicia, así como las actuaciones que de modo razonable reclame la víctima" (Corte Constitucional, Sent. C-409/09, p. 5). Para garantizar los mencionados derechos, se puede ejercer la denominada 'acción directa de la víctima del daño ambiental' en contra del asegurador, es decir, las víctimas del daño producido en una explotación minera pueden demandar judicialmente en un mismo proceso al productor directo del daño, así como también al asegurador de la persona natural o jurídica causante de este (Código de Comercio, art. 1033). ${ }^{26}$

Lo anterior de acuerdo con las tendencias evolutivas de la responsabilidad civil, que promueven el derecho a la reparación integral de las víctimas; no obstante, "[...] la finalidad del seguro no puede confundirse con la de la preservación del ecosistema, porque su deterioro no lo previene el seguro" (Zornosa, 2000). Los beneficiarios del seguro ecológico son las personas naturales o jurídicas afectadas por el daño generador de perjuicios patrimoniales y extrapatrimoniales; los primeros, divididos en daño emergente y lucro cesante, y los segundos, los perjuicios extrapatrimoniales o inmateriales, clasificados en morales, perjuicios a la salud y la pérdida de la oportunidad. La víctima, quien es beneficiaria de la póliza, puede ser directa o indirecta, porque los causahabientes o familiares de la víctima directa también tienen la categoría

\footnotetext{
${ }^{26}$ La norma comercial indica lo siguiente: "En el seguro de responsabilidad civil los damnificados tienen acción directa contra el asegurador. Para acreditar su derecho ante el asegurador de acuerdo con al artículo 1077, la víctima en ejercicio de la acción directa podrá en un solo proceso demostrar la responsabilidad del asegurado y demandar la indemnización del asegurador" (Código de Comercio, art. 1033).
} 
de beneficiarios del seguro. A su vez, el Estado es también beneficiario de la indemnización y, en ese caso concreto, "[...] el monto de la indemnización deberá destinarse a la reparación, reposición o restauración de los recursos naturales o ecosistemas deteriorados" (Congreso de la República de Colombia, Ley 23 de 1973, art. 5).

En suma, se instituye en una obligación de la empresa o de la persona natural abstenerse de causar un daño en la actividad que corresponda a la explotación minera, por ejemplo, en el territorio nacional o fuera de él; es decir, se debe evitar la ocurrencia del siniestro irreparable de naturaleza ambiental que perjudique al Estado colombiano o a la nación vecina. Así mismo, "cuando las actividades de reparación, reposición o restauración no sea posible realizarlas, el monto de la indemnización será invertido directamente en proyectos ecológicos o ambientales de especial interés para la comunidad afectada" (Congreso de la República de Colombia, Ley 23 de 1973, art. 5º).

\subsubsection{Los intermediarios del seguro ecológico}

Los intermediarios de seguros son personas naturales o jurídicas cuya actividad está centrada de manera exclusiva y excluyente a la comercialización de un producto: el seguro; en este caso, el seguro ecológico que cubre los daños causados a terceros y los generados al tomador o asegurado. Los intermediarios que comercializan el seguro ecológico son tres: en primer lugar, se encuentra el agente de seguros, quien es una persona natural con categoría de comerciante, que tiene los conocimientos técnicos para asesorar al potencial causante de daños ambientales; en segundo lugar, el agente de seguros, persona jurídica constituida como sociedad de responsabilidad limitada o colectiva; y, por último, el corredor de seguros o el denominado insurance broker. El nombrado corredor es una

persona física o jurídica que realiza la actividad mercantil de mediación de seguros privados sin mantener vínculos contractuales que supongan afección con entidades aseguradoras, y que ofrece asesoramiento independiente, profesional e imparcial a quienes demanden la cobertura de los riesgos a que se encuentran expuestos sus personas, sus patrimonios, sus intereses o responsabilidades [...] Los corredores de seguros deberán informar a quien trate de concertar el seguro sobre las condiciones del contrato que a su juicio conviene suscribir 
y ofrecer la cobertura que, de acuerdo a su criterio profesional, mejor se adapte a las necesidades de aquel; asimismo, velarán por la concurrencia de los requisitos que ha de reunir la póliza de seguro para su eficacia y plenitud de efectos (Mapfre, 2014).27

A continuación, se hace referencia a los reaseguradores, en su calidad de intervinientes en el contrato de seguro ecológico, mas no intermediarios de este.

\subsubsection{El reasegurador}

En términos sencillos, se puede afirmar que el reasegurador es la persona jurídica que asegura el patrimonio del asegurador, quien le cede de forma total o parcial el riesgo trasladado por el tomador o asegurado. Por ejemplo, la compañía minera, en calidad de tomadora en el seguro ecológico, le traslada el riesgo a la compañía aseguradora a cambio del pago de una prima, y, a su vez, dicha compañía de seguros descarga el riesgo trasladado por el tomador a la reaseguradora. Por medio del contrato de reaseguro, el asegurador protege su patrimonio, que puede ser afectado como consecuencia de la ocurrencia del siniestro, es decir, del daño ambiental generador de perjuicios.

El Estado, a través del Ministerio de Ambiente, Vivienda y Desarrollo Territorial, ha resaltado la importancia de contar con un adecuado reaseguro, y, a su vez, establecer apropiadas coberturas y valores asegurables proporcionales al riesgo trasladado. No es suficiente que se contrate un seguro ecológico por parte del tomador o asegurado, y que el asegurador al mismo tiempo descargue el riesgo

27 "Igualmente, vendrán obligados durante la vigencia del contrato de seguro en que hayan intervenido a facilitar al tomador, al asegurado y al beneficiario del seguro la información que reclamen sobre cualquiera de las cláusulas de la póliza y, en caso de siniestro, a prestarles su asistencia y asesoramiento [...] El pago del importe de la prima efectuado por el tomador del seguro al corredor no se entenderá realizado a la entidad aseguradora, salvo que, a cambio, el corredor entregue al tomador del seguro el recibo de prima de la entidad aseguradora [...] Para ejercer la actividad de corredor de seguros, será precisa la previa inscripción en el Registro Administrativo Especial de Mediadores de Seguros, Corredores de Reaseguros y de sus Altos Cargos"(Mapfre, 2014).

"Las relaciones con las entidades aseguradoras derivadas de la actividad de mediación del corredor de seguros se regirán por los pactos que las partes acuerden libremente, sin que dichos pactos puedan en ningún caso afectar a la independencia del corredor de seguros [...] Las relaciones de mediación de seguros entre los corredores de seguros y su clientela se regirán por los pactos que las partes acuerden libremente y supletoriamente por los preceptos que el Código de Comercio dedica a la comisión mercantil [...] La retribución que perciba el corredor de seguros de la entidad aseguradora por su actividad de mediación de seguros revestirá la forma de comisiones"(Mapfre, 2014). 
a un asegurador, lo imprescindible es suscribir la póliza con coberturas adecuadas, con exclusiones mínimas y con valores asegurados y límites de indemnización proporcionales al riesgo trasladado, por la persona natural o jurídica potencial generadora del daño ambiental. Así mismo, es relevante hacer uso de sistemas de ocurrencia y reclamación del siniestro, al que se hace referencia a continuación.

\subsubsection{El sistema 'claims made' en el seguro ecológico}

Al momento de la suscripción de la póliza de responsabilidad civil, comienza a ser recurrente la cobertura de riesgos generados en la empresa, incluyendo los riesgos ambientales inherentes al desarrollo del objeto social de las compañías. La póliza denominada Comprehensive General Liability (CGL) es un ejemplo de amparo destinado al pago de los perjuicios derivados de la responsabilidad civil en que incurran las empresas, y está "[...] destinada a la cobertura de la contaminación directamente accidental, contaminación que resulta de un hecho eventual y fortuito"(Pinilla, 2003, pp.157-179). En la citada póliza CGL, la contaminación es definida como un daño al medio ambiente, el cual es factible identificar de manera concreta en el momento de la ocurrencia del siniestro, con el agravante de no permitir el aseguramiento de las consecuencias que se puedan generar a largo plazo. Por ende, este seguro únicamente tiene un cubrimiento de daños concretos y presentes, y, “[...] en cuanto a la delimitación temporal, el período de garantía es del tipo occurrence y cubre los siniestros sobrevenidos dentro del período de garantía" (Malaval, 1999, pp.30-31).

Sin embargo, el daño ecológico generado por la empresa o persona natural tomadora o asegurada de la póliza puede exteriorizarse con posterioridad al hecho medioambiental culposo o doloso; es decir, el hecho contaminante ocurre en un tiempo determinado, pero los perjuicios se presentan con posterioridad, por ejemplo, después de dos o más años. Por esta razón, se incorpora por parte de las empresas aseguradoras el sistema claims made, que permite al asegurador nacional e internacional incrementar de forma importante su capacidad de reacción cuando se presenten eventos dañosos que se exterioricen en el futuro.

El hecho generador del daño ecológico puede manifestarse en el mismo momento de la ocurrencia del hecho; no obstante, el daño o la demanda de indemnización de este en contra del agente contaminador asegurado puede presentarse con posterioridad. Por esa razón, el sistema claims se instituye para 
manejar de manera eficiente este inconveniente, donde pueden suceder siniestros tardíos o latentes (Comerio, 2010, pp. 30-31).

\section{Conclusiones}

En la investigación realizada, se encontró que el Estado colombiano busca, a través de normas, reglas y principios, la protección de los recursos naturales de la nación; normas de carácter constitucional y legal, expedidas para proteger el medio ambiente en todos los contextos. Se identificó que el citado medio ambiente es catalogado como un derecho humano, que trata de ser salvaguardado por la comunidad internacional. No obstante, uno de los hallazgos más significativos fue el hecho de comprobar que, al ponderar los derechos al medio ambiente sano con la explotación de los recursos naturales, este último prevalece sobre el primero, situación que se considera reprochable.

A su vez, se descubrió que el Estado expidió una norma especial que regula el seguro ecológico, y lo clasifica en obligatorio y voluntario. Al hacer el estudio acerca del citado seguro, se identificó que el propósito de la celebración del contrato es la protección del patrimonio del potencial causante de daños sobre el medio ambiente, $y$, a su vez, garantizar el derecho fundamental a la indemnización integral a las víctimas de este. Sin embargo, se concluyó que la norma no incorpora disposiciones que tengan la intención de identificar, prevenir y amparar al medio ambiente.

\section{Bibliografía}

Adzel Riba, J. (1987). Cómo se trabaja la piel. Barcelona: Editorial De Vecchi. Asociación de Aseguradores de Chile A.G. Cobertura de responsabilidad civil por contaminación, adicional a: póliza de responsabilidad civil POL 197008.

Asociación de Aseguradores de Chile A.G. Póliza de responsabilidad civil. CAD 197009. Res. 211 del 17/07/1997.

Asthon, T. S. (1989). La Revolución Industrial. México: Fondo de Cultura Económica.

Chavarro,J. (2010). Licencias y protección de los recursos naturales. Bogotá: Editorial Nueva Legislación.

Cherni,J. (2006). Reseña de Worlds apart. Globalization and the environment de James Gustave Speth (ed.). Buenos Aires: Red Theomai.

Colombia, Congreso de la República. (2013). Constitución Política de Colombia. Bogotá, D.C.: Editorial Legis. 
Colombia, Congreso de la República. Código Penal, 1999.

Colombia, Congreso de la República. Decreto 2811 de 1974. Por el cual se dicta el Código Nacional de Recursos Naturales Renovables y de Protección al Medio Ambiente.

Colombia, Congreso de la República. Ley 23 de 1973. Por la cual se conceden facultades extraordinarias al Presidente de la República para expedir el Código de Recursos Naturales y de Protección al Medio Ambiente y se dictan otras disposiciones.

Colombia, Corte Constitucional. Expediente D-8422 del 31 de agosto de 2011. M. P.: Jorge Iván Palacio.

Colombia, Corte Constitucional. Sentencia C-288 de 2012. Expediente D-8690. M. P.: Luis Ernesto Vargas Silva.

Colombia, Corte Constitucional. Sentencia C-339 de 2002. M. P.: Marco Gerardo Monroy Cabra.

Colombia, Corte Constitucional. Sentencia C-409 de 2009. M. P.: Juan Carlos Henao Pérez.

Colombia, Corte Constitucional. Sentencia C-443 de 2009. M. P.: Nilson Elías Pinilla Pinilla.

Colombia, Corte Constitucional. Sentencia C-651 de 2003. M. P.: Jaime Araújo Rentería.

Colombia, Corte Constitucional. Sentencia T-419 de 1992. M. P.: Simón Rodríguez Rodríguez.

Colombia, Corte Constitucional. Sentencia T-851 de 2010. M. P.: Humberto Antonio Sierra Porto.

Comerio, J. J. (2010). Coloquio Seguros E Justicia; cobertura en base claims made. Desafios, necesidad, funcionamiento. Miami: General RE.

Díaz Carela, D., \&Méndez, F.C. (2011). Hacia una ética de la biosfera para la crisis ambiental. Madrid: Universidad Complutense de Madrid.

Esguerra Portocarrero, J. C. (2004). La protección constitucional del ciudadano. Bogotá: Legis Editores S.A.

Galvis Segura, S. (marzo, 1999). El seguro de contaminación en el mercado internacional de reaseguros. Ponencia presentada en el Foro sobre Seguro Ecológico, Especialización de Derecho del Medio Ambiente y Centro de Estudios de Derecho de Seguros, Universidad Externado de Colombia, Bogotá.

Gamboa Berna, G. A (2011). "La Tierra: un planeta posible para siete mil millones y más”. Persona y Bioética, 15(2), 101-106. 
Geary, M. (2006). "El conflicto de las papeleras". Revista Otro Sur, 5.

Ghersi, C. (1995). Modernos conceptos de responsabilidad civil. Medellín: Biblioteca Jurídica Diké.

González, A. (2012). La seguridad nuclear: escenarios posibles tras Fukushima. Argentina: Academia Nacional de Ingeniería (ANI).

Jankilevich, S. (2003). Las cumbres mundiales sobre el ambiente. Estocolmo, Rio y Johannesburgo. 30 años de historia ambiental. Argentina: Universidad de Belgrano. Jaquenod de Zsögön, S. (2004). Derecho ambiental. Madrid: Dykinson.

Malaval, F. (1999). Développement durable, assurances et environnement. París: Ed. Económica.

Mapfre. (2014). Diccionario Mafpre de seguros. Madrid: Fundación Mapfre. Recuperado de http://www.mapfre.com/wdiccionario/terminos

Medina Pabón,J. (2009). “Hacia una nueva teoría de la responsabilidad”. Revista Estudios Socio-Jurídicos, 7(1), 165. Bogotá: Universidad del Rosario.

Narváez Bonnet, J. (2000). "De la responsabilidad civil por el daño ambiental y el seguro ecológico en Colombia”. Revista Ibero-Latinoamericana de Seguros, 15.

Nique, M. (2010). "Biodiversidad: clasificación y cuantificación”. Tingo María, Perú: Universidad Nacional Agraria de la Selva.

PBI Colombia. (2011). Minería en Colombia: ¿̨a qué precio? Bogotá: PBI.

Pinilla Rodríguez,F.(2003). "Algunas consideraciones en torno al seguro ambiental: panorama comparado y situación dentro del sistema de evaluación de impacto ambiental vigente en Chile". Rev. Derecho (Valdivia), 15, 157-179.

Rodríguez R., Narran, F., \&Alonso, B. (1997). Mecanismos jurídicos de la protección ambiental. Bogotá: Ediciones Jurídicas Gustavo Ibáñez.

Sáchica, L. C., \& Vidal Perdomo, J. (1991). La constituyente de 1991. Bogotá: Cámara de Comercio.

Salazar Vargas, C. (2009). La definición de política pública. Ciudad de México: Fundación Preciado.

Tommasino, H., \& Foladori, G. (2006). Certezas sobre la crisis ambiental. Buenos Aires: Red Theomai.

Velásquez Gavilanes, R. (2009). “Hacia una nueva definición del concepto política pública”. Revista Desafíos, 20, 149-187. Bogotá: Universidad del Rosario.

Zornosa Prieto, H. (2000). “Comentarios a la Ley colombiana No 491 del seguro ecológico expedida el 13 de enero de 1999. En AA.vv., Lecturas sobre derecho del medio ambiente. T. 1". Bogotá: Universidad Externado de Colombia. 
Este libro fue compuesto en caracteres Adobe Caslon Pro

11,5 puntos, impreso sobre papel propal de 70 gramos y encuadernado con método hot melt, en septiembre de 2015, en Bogotá, D. C., Colombia. 